\title{
A Quantitative Study Exploring the Social Determinants of Health in the North West Region of Cameroon
}

\author{
Joel Ngwa Ambebila ${ }^{1}$, Ebenezer Obi Daniel ${ }^{1}$, Paul Olaiya Abiodun ${ }^{1}$, Israel Olukayode Popoola ${ }^{2}$, \\ Stellamaris Moronkeji ${ }^{1}$, Olayinka Victor Ojo ${ }^{1}$, Ahmed Mamuda Bello ${ }^{1}$, Christie Omolola Adams ${ }^{1}$ \\ ${ }^{1}$ Department of Public Health, School of Public Health, Texila American University, Georgetown, Guyana \\ ${ }^{2}$ Department of Epidemiology and Community Health, Faculty of Clinical Sciences, College of Medicine, University of Ilorin, Ilorin, Nigeria
}

Email address:

dannypressy@yahoo.com (E. O. Daniel)

\section{To cite this article:}

Joel Ngwa Ambebila, Ebenezer Obi Daniel, Paul Olaiya Abiodun, Israel Olukayode Popoola, Stellamaris Moronkeji, Olayinka Victor Ojo, Ahmed Mamuda Bello, Christie Omolola Adams. A Quantitative Study Exploring the Social Determinants of Health in the North West Region of Cameroon. Journal of Family Medicine and Health Care. Vol. 6, No. 1, 2020, pp. 8-14. doi: 10.11648/j.jfmhc.20200601.12

Received: January 15, 2020; Accepted: January 27, 2020; Published: February 12, 2020

\begin{abstract}
Health and wellbeing are shaped by social and economic factors. These factors are known as Social Determinants of Health and are defined as the conditions in which people are born, grow, live, work and age. A number of factors shape wellbeing including distribution of money, power, and resources both at global, national and local level. The purpose of this study was to explore the social determinants of health and health disparities amongst patients who seek health services in health facilities of the North West Region of Cameroon. The study was a cross sectional survey that used a structured questionnaire to collect quantitative data from 430 participants. The main findings of the study show that the vicious cycle of interactions between low educational levels, low income levels and poverty reinforces a pattern of social disadvantages, health inequalities and ill health in the targeted communities. There were some factors identified that put poor communities at a health disadvantage; these included unemployment (43.5\%) low income levels (43.8\%) and low educational levels (40\%). These factors contribute to the social and economic inequalities amongst communities. In conclusion, the study showered that social determinants of health are important factors for understanding health care outcomes. There is the need to further use a larger dataset to explore the effectiveness and progress towards health equity related to social determinants of health in Cameroon.
\end{abstract}

Keywords: Social Determinants of Health, Health Facilities, Cameroon

\section{Introduction}

The health care system is a small part of what shapes health and wellbeing. Health and wellbeing are shaped by social and economic factors. These factors are known as Social determinants of Health and are defined as the conditions in which people are born, grow, live, work and age. A number of factors shape wellbeing including distribution of money, power, and resources both at global, national and local level. The World Health Organization classifies health determinants as either structural or intermediary. Structural determinants of health include: Income, Education, Employment, working conditions, gender, race/ethnicity, and culture. These structural determinants define an individual's socioeconomic position and act through a set of intermediary determinants to shape health outcomes which include material and psychosocial circumstances. Material determinants include factors such as: housing, food security and physical environment while psychosocial determinants include factors such as Social environment, social support, personal health practices/coping skills and healthy child development.

It has been projected that the current 3.3 billion urban populations is expected to grow to 4.9 billion by 2030 , with most of this rapid growth occurring in the urbanized areas of Africa and Asia [1]. Studies have been done to analyze health patterns and health access in slum communities. Results of these studies have highlighted similarities across the world. These similarities have been demonstrated in Nairobi including poor health outcomes and financial barriers to health care [2]. A number of social needs play a significant role in health status and life expectancies. Some of these needs include safe housing and food security. Addressing 
these unmet social needs is critical in optimizing patient's health [3].

During the past two decades, the public health community's attention has been drawn increasingly to the social determinants of health, the factors apart from medical care that can be influenced by social policies and shape health in powerful ways. A large and compelling body of evidence has been accumulated, particularly during the last two decades, which reveals a powerful role for social factors apart from medical care in shaping health across a wide range of health indicators, settings, and populations [4]. This evidence does not deny that medical care influences health; rather, it indicates that medical care is not the only influence on health and suggests that the effects of medical care may be more limited than commonly thought, particularly in determining who becomes sick or injured in the first place [5, 6 and 7]. The relationships between social factors and health, however, are not simple, and there are active controversies regarding the strength of the evidence supporting a causal role of some social factors.

People with illness most often live in chronic poverty. Conversely, poverty can be a significant risk factor for poor health. The relationship between poverty and illness is both straightforward and complex. Understanding this broader context is key to addressing poverty in order to promote health and support the recovery of persons with illness [6]. Having a stable income, either from employment or through financial support and benefits, is directly related to other determinants of health, namely affordable housing and rent, food and transportation to access healthcare [8]. Social inclusion, or the ability to engage fully in the community, is also somewhat dependent on available finances [9].

Education is a frequently used indicator in epidemiology. As formal education is frequently completed in young adulthood and is strongly determined by parental characteristics [10]. It can be conceptualized within a life course framework as an indicator that in part measures early life socioeconomic position. Education can be measured as a continuous variable (years of completed education) or as a categorical variable by assessing educational milestones, such as completion of primary secondary or high school, higher education diplomas, or degrees. Although education is often used as a generic measure of socioeconomic position and also a social determinant of health, specific interpretations explain its association with health outcomes.

Occupation-based indicators of socioeconomic position are widely used in social studies. Kunst and Mackenbach emphasize that this measure is relevant, because it determines people's place in the societal hierarchy and not just because it indicates exposure to specific occupational risk, such as toxic compounds [11]. Occupation (parental or own adult) is strongly related to income and, therefore, the association with health may be one of a direct relation between material resources, the monetary and other tangible rewards for work that determines material living standards and health. Occupations reflect social standing and may be related to health outcomes because of certain privileges such as easier access to better health care and access to education. Occupation may reflect social networks, work based stress, control and autonomy, and, thereby, affect health outcomes through psychosocial processes. Occupation may also reflect specific toxic environmental or work task exposures, such as physical demands (e.g. transport driver or labourers).

Poor housing quality and instability have been associated with numerous physical health conditions, including respiratory conditions due primarily to poor indoor air quality, cognitive delays in children from exposure to neurotoxins like lead and accidents and injuries as a result of structural deficiencies [12, 13]. Housing instability disrupts work, school, and day care arrangements, as well as social networks of both parents and children. Worries over the stability of one's housing situation and poor control over the conditions of one's home can result in distress and subsequent mental disorders. Children and adults experience poor housing quality and instability differently, with further variations among children depending on their developmental stage. As housing conditions are tied to economic factors, vulnerable populations (i.e., racial/ethnic minorities, families with young children, the elderly and low-income households) are most likely to be housing insecure and suffer health consequences related to poor housing conditions, residential instability and unaffordable housing expenses [14].

Social Environment, including psychosocial stressors (for example, negative life events and job strain), stressful living circumstances like. high debt and lack of social support, coping styles, etc. people are exposed in different degrees of experiences and life situations that are perceived as threatening, frightening and difficult for coping in the everyday. This partly explains the long-term pattern of social inequalities in health. Stress may be a causal factor and a trigger that directs many forms of illness; and detrimental, long-term stress may also be part of the causal complex behind many somatic illnesses. A person's socioeconomic position may itself be a source of long-term stress, and it will also affect the opportunities to deal with stressful and difficult situations.

\section{Methods}

\subsection{Study Setting}

The study was undertaken in four health facilities in the North West Region of Cameroon. Participants were from rural settings (Azire Integrated Health Center, Nkwen Rural Health Center) and urban settings (Nkwen Baptist Health Center and Bamenda District Hospital). The North West Region of Cameroon is well known for its scenic hilly locations, cold climate and rugged relief, which render communication difficult. Facilities included public district hospitals and primary health centres; private health care facility (mission health centre). Inhabitants in the targeted communities were mostly English and Pidgin English speakers with the major source of income being subsistence 
farming.

\subsection{Data Collection Methods}

This is a quantitative study based on exit pool interviews. Interviews were conducted in the English and Pidgin English languages depending on which language the participant was more comfortable. The interviews were carried out by trained data collectors. The data collection took place from August 2019 until October 2019. Prior to data collection, a pilot study was done in a different health facility reaching 40 participants. This pilot study permitted the research team to correct the data collection tools and also correct the phrasing in the questionnaires to be better understood.

\subsection{Study Participants}

Study participants were recruited from patients and care givers seeking health care services in the targeted health facilities. The minimum sample size for the number of patients who were interviewed was calculated using the Leslie and Kish formula for descriptive studies. [15]

$$
\mathrm{N}=\mathrm{P}(1-\mathrm{P}) \mathrm{Z} 2 / \mathrm{D} 2
$$

Where $\mathrm{N}$ is the minimum sample size needed

$\mathrm{D}$ is the level of error that can be tolerated ( 0.05 chance of error) and CI 95\%

$\mathrm{P}$ is the estimated prevalence rate $(50 \%)$.

$\mathrm{Z}$ is the standard variation corresponding to confidence level. At confidence level of $95 \%, Z=2$

$$
\begin{aligned}
& \mathrm{N}=0.5(1-0.5) 22 / 0.052 \\
& \mathrm{~N}=400
\end{aligned}
$$

To allow for a non-response rate of $10 \%$ (40 respondents), the sample size was increased by 40 to make 440 respondents. The sample size was consistent and realizable when compared with the target population.

\subsection{Ethical Considerations}

Ethical approval for the study was obtained from the Cameroon Baptist Convention Health Board Institutional Review Board while administrative clearance was obtained from the North West Regional Delegation for Public Health. All participants gave their informed consent before participating in the study, and their anonymity, privacy and confidentiality was respected. A written consent was obtained from each participant of the study.

\subsection{Data Management and Analysis}

Data from exit pool was coded and fed into Statistical Package for Social Sciences (SPSS) soft-ware, for analysis. Descriptive statistical analysis was used to summarize information and explore the data for the distribution of responses. Microsoft excel spread sheet was used to provide means, frequency and drawing various charts. Inferential statistics of Chi square and Wilcoxon were used to test association between variables as appropriate.

\begin{tabular}{|c|c|c|c|c|c|c|c|}
\hline \multirow{2}{*}{ Variable } & & \multicolumn{2}{|c|}{ Urban $(n=318)$} & \multicolumn{2}{|c|}{ Rural (n=112) } & \multicolumn{2}{|c|}{ Together $(n=430)$} \\
\hline & & $\mathbf{n}$ & $\%$ & $\mathbf{n}$ & $\%$ & n & $\%$ \\
\hline \multicolumn{8}{|l|}{ Sex } \\
\hline & Male & 105 & $33,0 \%$ & 16 & $14,3 \%$ & 121 & $28,1 \%$ \\
\hline & Female & 213 & $67,0 \%$ & 96 & $85,7 \%$ & 309 & $71,9 \%$ \\
\hline \multicolumn{8}{|c|}{ Age group } \\
\hline & $20-30$ & 30 & $9,4 \%$ & 12 & $10,7 \%$ & 42 & $9,8 \%$ \\
\hline & $31-40$ & 133 & $41,8 \%$ & 66 & $58,9 \%$ & 199 & $46,3 \%$ \\
\hline & $41-50$ & 110 & $34,6 \%$ & 21 & $18,8 \%$ & 131 & $30,5 \%$ \\
\hline & More than 50 & 45 & $14,2 \%$ & 13 & $11,6 \%$ & 58 & $13,5 \%$ \\
\hline \multicolumn{8}{|c|}{ Marital status } \\
\hline & Married & 156 & $49,1 \%$ & 61 & $54,5 \%$ & 217 & $50,5 \%$ \\
\hline & Divorced & 2 & $0,6 \%$ & 0 & $0,0 \%$ & 2 & $0,5 \%$ \\
\hline & Widowed & 13 & $4,1 \%$ & 2 & $1,8 \%$ & 15 & $3,5 \%$ \\
\hline & Single & 143 & $45,0 \%$ & 47 & $42,0 \%$ & 190 & $44,2 \%$ \\
\hline & Free union & 4 & $1,3 \%$ & 2 & $1,8 \%$ & 6 & $1,4 \%$ \\
\hline \multicolumn{8}{|c|}{ Level of education } \\
\hline & No School & 9 & $2,8 \%$ & 2 & $1,8 \%$ & 11 & $2,6 \%$ \\
\hline & Primary School & 62 & $19,5 \%$ & 15 & $13,4 \%$ & 77 & $17,9 \%$ \\
\hline & Secondary School & 60 & $18,9 \%$ & 24 & $21,4 \%$ & 84 & $19,5 \%$ \\
\hline & High School & 56 & $17,6 \%$ & 22 & $19,6 \%$ & 78 & $18,1 \%$ \\
\hline & Studied a trade & 15 & $4,7 \%$ & 3 & $2,7 \%$ & 18 & $4,2 \%$ \\
\hline & University & 116 & $36,5 \%$ & 46 & $41,1 \%$ & 162 & $37,7 \%$ \\
\hline \multicolumn{8}{|c|}{ Work Situation } \\
\hline & Unemployed not seeking for work & 66 & $20,8 \%$ & 24 & $21,4 \%$ & 90 & $20,9 \%$ \\
\hline & Unemployed and seeking for work & 54 & $17,0 \%$ & 43 & $38,4 \%$ & 97 & $22,6 \%$ \\
\hline & Part time work & 83 & $26,1 \%$ & 23 & $20,5 \%$ & 106 & $24,7 \%$ \\
\hline & Full time work & 115 & $36,2 \%$ & 22 & $19,6 \%$ & 137 & $31,9 \%$ \\
\hline \multicolumn{8}{|c|}{ Monthly income } \\
\hline & No regular income & 122 & $38,4 \%$ & 74 & $66,1 \%$ & 196 & $45,6 \%$ \\
\hline
\end{tabular}

\section{Results}

Table 1. Comparison of participant's socio demographic variables. 


\begin{tabular}{|c|c|c|c|c|c|c|}
\hline \multirow{2}{*}{ Variable } & \multicolumn{2}{|c|}{ Urban $(n=318)$} & \multicolumn{2}{|c|}{ Rural (n=112) } & \multicolumn{2}{|c|}{ Together $(n=430)$} \\
\hline & $\mathbf{n}$ & $\%$ & $\mathbf{n}$ & $\%$ & n & $\%$ \\
\hline Less than 50,000 Frs & 83 & $26,1 \%$ & 17 & $15,2 \%$ & 100 & $23,3 \%$ \\
\hline $50,000-100,000$ Frs & 54 & $17,0 \%$ & 7 & $6,3 \%$ & 61 & $14,2 \%$ \\
\hline $100,000-150,000$ Frs & 21 & $6,6 \%$ & 6 & $5,4 \%$ & 27 & $6,3 \%$ \\
\hline $150,000-200,000$ Frs & 22 & $6,9 \%$ & 5 & $4,5 \%$ & 27 & $6,3 \%$ \\
\hline $200,000-300,000$ Frs & 13 & $4,1 \%$ & 2 & $1,8 \%$ & 15 & $3,5 \%$ \\
\hline Above 300,000 Frs & 3 & $0,9 \%$ & 1 & $0,9 \%$ & 4 & $0,9 \%$ \\
\hline
\end{tabular}

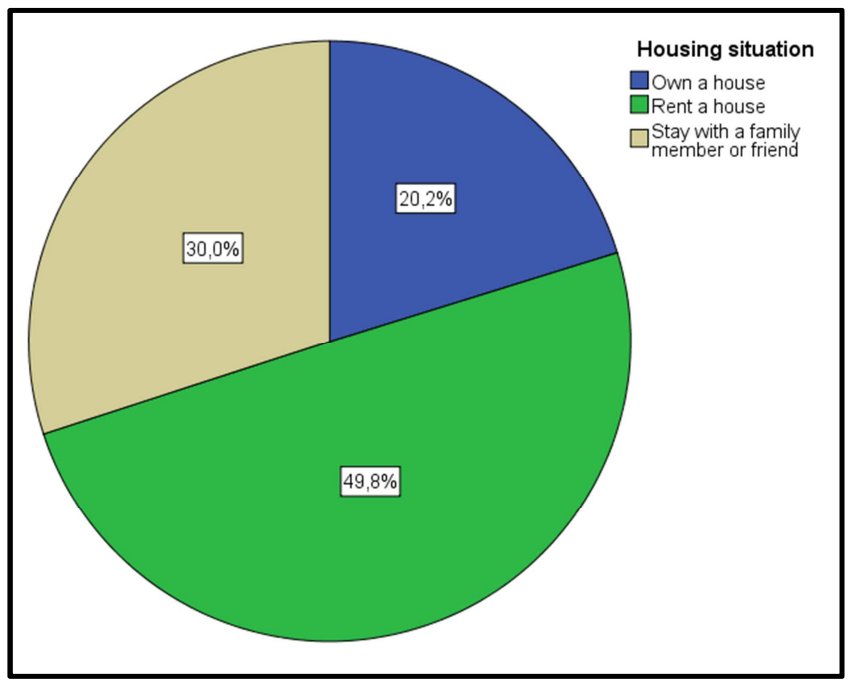

Figure 1. Housing situation of participants $(n=430)$.

Housing is one of the main social determinants of health. This factor determines the social status of people and people who own a house, are up on the social status. The study found that only $20.2 \%$ of participants owned a house while $49.8 \%$ of participants stayed with a friend or family member. The study also found that $30 \%$ or participants stayed in a rented house. This finding show that most of the population lived in relative poverty.

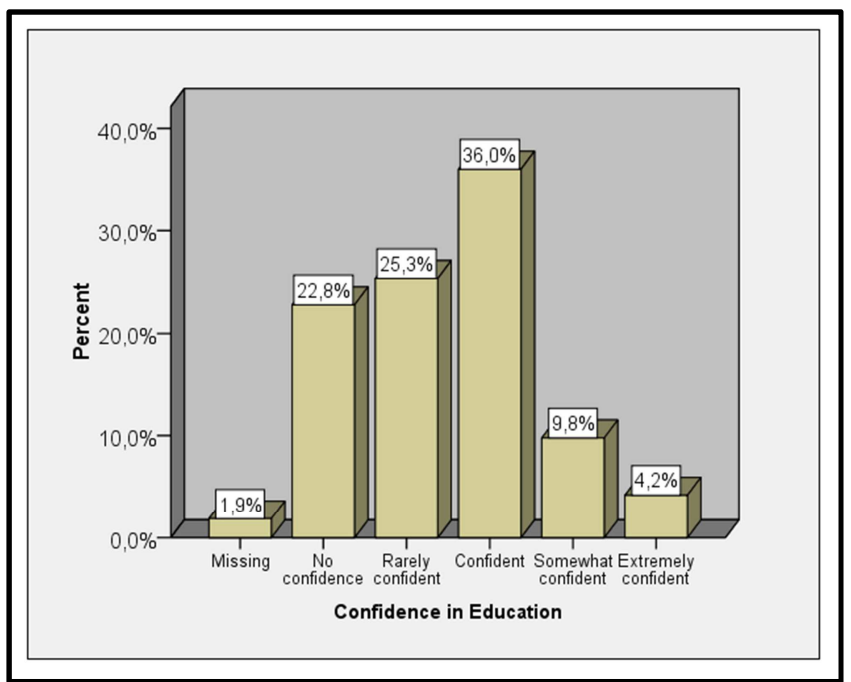

Figure 2. Confidence in Education $(n=430)$.

Figure 2 above shows how confident participants are with respect to the education in the community. Amongst the participants $22.8 \%$ of participants do not have confidence in the education they received while $4.2 \%$ had extreme confidence.

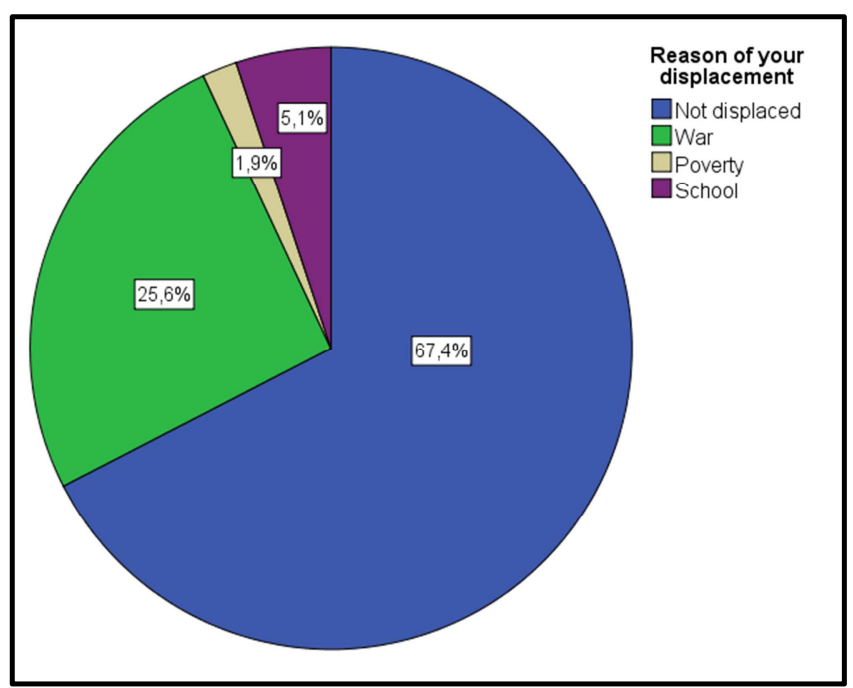

Figure 3. Displacements from home and reasons for displacements $(n=430)$.

Displacements were one of the social factors evaluated. The study found that $32.6 \%$ of participants were displaced from their homes while $67.4 \%$ were not displaced. Of the displacements, $25.6 \%$ were displaced due to war and $1.9 \%$ were displaced due to poverty. There is a war going on in the community where this study was done and this factor came out during data collection.

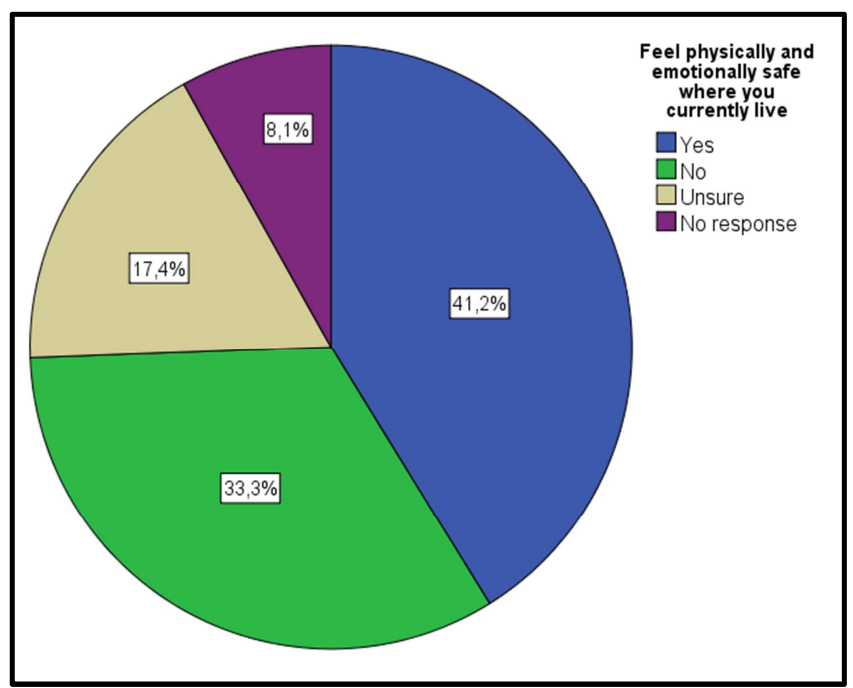

Figure 4. Physical and emotional safety $(n=430)$.

Emotional safety contributes in depression which is a social factor linked to how healthy a community can be. It 
was discovered that $33.3 \%$ or participants feel unsafe where they currently live while $41.2 \%$ feel physically and emotionally safe. Also, $17.4 \%$ of participants could not say if they are safe or unsafe.

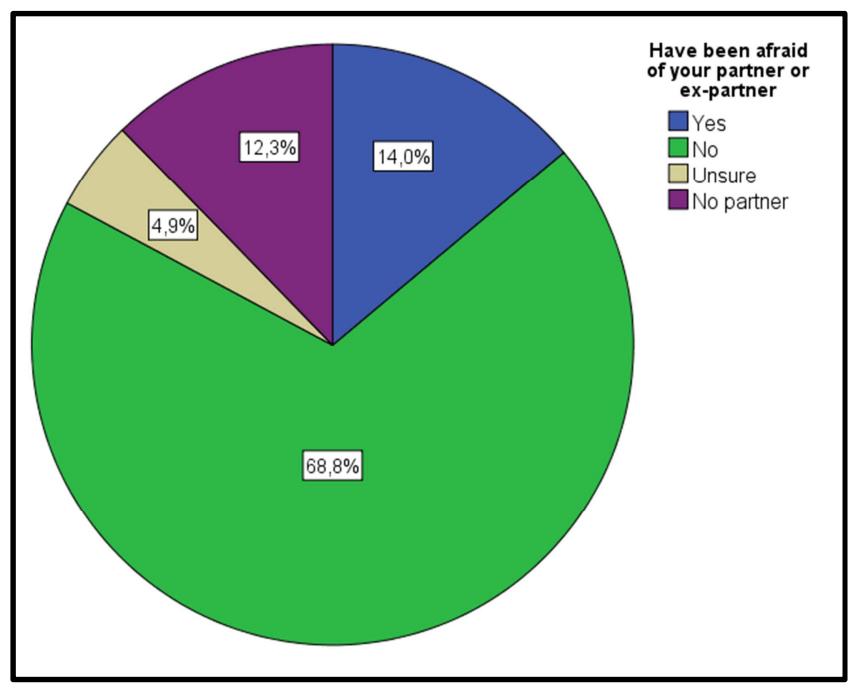

Figure 5. Afraid of partner $(n=430)$.

The study findings showed that $14 \%$ of participants are afraid of their partners while $68.8 \%$ are not afraid of their partners. It was also discovered that $4.9 \%$ are unsure and $12.3 \%$ of participants do not have partners.

\section{Discussions}

In this study, 443 participants were interviewed in four health facilities. Questionnaires where participants refused to continue were deleted; they represented 13 (2.9\%) of the participants. The final number of participants with complete information on key variables was 430 (97\%). Participants between the age bracket of 31-40 years represent the highest number of participants (46.3\%), while only 42 (9.8\%) were between 20-30 years of age. About half of the participants are married $(50.5 \%$ ) while $44.2 \%$ are single with $1.2 \%$ living in a free union. As for educational level, $17.9 \%$ of participants have had just primary education while $19.5 \%$ have had secondary education. The findings showed that $20.9 \%$ of participants were unemployed but not seeking for work while $22.6 \%$ were unemployed and seeking for work giving an unemployment rate of $43.5 \%$. These results show that the population is living in poverty with a high under scholarization and high unemployment rates.

The study showed that a majority of people living in the North West Region of Cameroon live in a vicious cycle of poverty. People have low incomes which intern make them not to have the means of educating themselves and their children. The study also showed that participants do not have confidence in the education they receive. Because of low education levels it makes it difficult for people to have decent jobs and thus lower standards of living. All this factors contribute in determining the health status of patients. This also led to health inequalities and health disparities. The study also showed that people who are more in need of health services do not have access to health care services. These findings have also been reported by Kunst and Mackenbach who reported that occupation determines people's place in the societal hierarchy and not just because it indicates exposure to specific occupational risk [11]. Occupation (parental or own adult) is strongly related to income and, therefore, the association with health may be one of a direct relation between material resources, the monetary and other tangible rewards for work that determines material living standards and health.

The social exclusion of the poor from society has been demonstrated across history whereby technological and industrial advances has made it possible for the more advantaged to distinct themselves from those in disadvantaged conditions $[16,22]$. The paradigm shifts from primary health care to social determinants of health in recent years have shifted health care service delivery from provision of essential medical service to consider a broader health policy framework which considers involving other sectors and stakeholders like municipal authorities and non-state actors. The findings of this research are also consistent with the findings from other studies across the world as highlighted in the introduction. This has highlighted a multidimensional nature of poverty and the impact it has on health inequalities and disparities amongst populations of the North West Region of Cameroon.

Though there has been increasing attention to the subject of inequalities in health and its impact on health outcome, there still exist huge differences in health amongst and within Countries $[19,5]$. In this study it was discovered that a great proportion of the population had difficulties seeking health care. Participants had difficulties going to health facilities others had difficulties paying their hospital bills. The study also found that people spend much time going to health facilities with some spending more than 1 hour to go to the health facilities.

Though it has been demonstrated that health disparity is a universal problem, the level to which socio demographic factors influence health varies from country to country and within social groups of the same country. A study of 22 European countries demonstrated that differences in mortality among those with the least versus the most education varied substantially across counties [20, 23]. From these study findings there is compelling evidence to be concerned about such health inequalities. The persistence of health inequalities based on social status raises moral concerns, offending many people's basic notion of fairness and justice when it comes to health and health outcomes.

The WHO recognizes social and health equity as a priority for good health outcomes. This has been reflected by the formation of the Commission on Social Determinants of Health in 2005. As stated by Marmot, This commission puts together and summarizes evidence worldwide on social determinants of health and recommends actions that address health inequities [21]. 


\section{Conclusion}

The study has examined the social determinants of health amongst populations of the North West Region of Cameroon. It is important that policy makers in Cameroon assess closely these socio economic factors which determine the health status of populations and contribute in health disparities in a bit to design policies that can remedy and promote increased access and patronage of healthcare facilities. The success in implementing any plan or solution towards a change in health disparities requires the full engagement and participation of the beneficiaries of such interventions from the onset through to the implementation and monitoring of the program. This intervention should have as objective the improvement of social standards of populations.

The findings of this study have implications for policy makers in Cameroon. The study findings have shown that there is an association between the social determinants of health and health outcomes. It is therefore important that when designing health policies particularly policies around health promotion, social determinants of health and health inequalities should be at the center stage. Politicians and those developing health policies at the ministry of health should understand these findings and use them to inform regional and national health policies.

\section{Limitations of This Study}

There is the need to further use a larger dataset to explore the effectiveness and progress towards health equity related to social determinants of health in Cameroon.

\section{Recommendations}

Based on the findings from this study, we recommend that:

i. The study be extended to other parts of the country to understand the social determinants of health covering the whole Country.

ii. More advance study using qualitative means to understand social determinants of health in Cameroon.

iii. Policy makers in Cameroon assess closely the social determinants of health in a bit to design policies that can remedy and promote increased access and patronage of healthcare services.

\section{Acknowledgements}

Our sincere appreciation goes to the participants of the study for their willingness to share their experiences with the research team. We also extend special thanks to the local authorities and health facilities for accepting that the study be done in their area of command and in their health facilities.

\section{References}

[1] United Nations Population Fund, (2007): Unleashing the Potential of Urban Growth UNFPA. State of World Population 2007. New York: UNFPA; 2007.
[2] Taffa N, Chepngeno G, (2005): Determinants of health care seeking for childhood illnesses in Nairobi slums. Trop Med Int Health 2005 Mar, 10 (3): 240-245.

[3] Koh H, Oppeenheimer S, Massin S, Emmons K, Geller A, Viswanath K, (2010): Translating research evidence into practice to reduce health disparities. A social determinants approach. AM J Public Health. 2010; 100 (Suppl 2) S72-S80.

[4] Marmot M, Bell R, (2012): Fair society, healthy lives. Public Health. 2012; 126 (Suppl 1): S 10.

[5] Braveman P, Egerter S, Williams DR, (2011): The social determinants of health: coming of age. Annu Rev Public Health. 2011; 32: 381-98.

[6] Braveman P, Egerter S, Barclay C, Princeton NJ, (2011): Income, wealth and health. Exploring the social determinants of health: Robert Wood Johnson Foundation; 2011. issue brief no. 4 .

[7] Braveman PA, Egerter SA, Woolf SH, Marks JS, (2011): When do we know enough to recommend action on the social determinants of health? Am J Prev Med. 2011; 40 (1 Suppl 1): S58-66.

[8] Raphael D, (2009): Social Determinants of Health. Canadian Perspectives 2009, (2nd ed.). Toronto, ON: Canadian Scholars' Press Inc.

[9] Mikkonen J, Raphael D, (2010): Social Determinants of Health: The Canadian Facts. Toronto, ON: York University School of Health Policy and Management.

[10] Bruna G, Mary S, Debbie A, John W, George D, (2004): Indicators of socioeconomic position. Journal of Epidemiology and community health. http://dx.doi.org/10.1136/jech.2004.023531.

[11] Kunst A, Mackenbach J, (2000): Measuring socioeconomic inequalities in Health. Copenhagen, WHO Regional Office Europe, 2000.

[12] Evans, GW, (2006): Child development and the physical environment. Annual Review of Psychology, 2006, 57, 423451. doi: 10.1146/annurev.psych.57.102904.190057.

[13] Leventhal, T, Newman S, (2010): Housing and child development. Children and Youth Services Review, 2010, 32, 1165-1174.

[14] Rauh, VA, Landrigan, PJ, Claudio L, (2008). Housing and health: intersection of poverty and environmental exposures. Annals of the New York Academy of Sciences, 2008, 1136, 276-288. doi: 1136/1/276 [pii].

[15] Kish, L.: Survey Sampling. John Wiley \& Sons, Inc., New York, London 1965, IX+643 S., 31 Abb., 56 Tab., Preis 83 s.

[16] UN Habitat The Challenge of Slums: Global Report on Human Settlements; 2003. http://www.unhabitat.org/downloads/docs/GRHS.2003.2.pdf.

[17] Marmot M, Friel S, Bell R, Tanja A, Houweling J, Taylor S (2008): on behalf of the Commission on Social Determinants of Health: Closing the gap in a generation: health equity through action on the social determinants of health. Lancet 2008, 372: 1661-1669.

[18] WHO: World Health Report 2008 Primary Health care. Geneva: WHO; 2008. 
[19] Murray CJ, Gakidou EE, Frenk J. (1999): Health inequalities and social group differences: what should we measure? Bull World Health Organ. 1999; 77 (7): 537-43.

[20] Mackenbach JP, Stirbu I, Roskam AJ, Schaap MM, Menvielle G, Leinsalu M, Kunst AE. (2008): European Union Working Group on Socioeconomic Inequalities in Health. Socioeconomic inequalities in health in 22 European countries. N Engl J Med. 2008 Jun 5; 358 (23): 2468-81.

[21] Marmot M, Friel S, Bell R, Houweling TA, Taylor S. (2008): Commission on Social Determinants of Health. Closing the gap in a generation: health equity through action on the social determinants of health. Lancet. 2008 Nov 8; 372 (9650): 1661-9.
[22] Patrick O'Donnell, Diarmuid O'Donovan, and Khalifa Elmusharaf (2018): Measuring social exclusion in healthcare settings: a scoping review Int J Equity Health. 2018; 17: 15.

[23] Addi P L van Bergen, Judith R L M Wolf, Mariam Badou, Kimriek de Wilde-Schutten, Wilhelmina IJzelenberg, Hanneke Schreurs, Bouwine Carlier, Stella J M Hoff, Albert M van Hemert (2019): The association between social exclusion or inclusion and health in EU and OECD countries: a systematic review. European Journal of Public Health, Volume 29, Issue 3, June 2019, Pages 575-582, https://doi.org/10.1093/eurpub/cky143. 